\title{
Cognitive-enhancing effects of hydrolysate of polygalasaponin in SAMP8 mice
}

\author{
Pan $\mathrm{XU}^{1}$, Shu-ping $\mathrm{XU}^{1}$, Ke-zhu WANG ${ }^{1}$, Cong $\mathrm{LU}^{1}$, Hong-xia $\mathrm{ZHANG}^{2}$, Rui-le $\mathrm{PAN}^{1}$, \\ Chang $\mathrm{QI}^{1}$, Yan-yan $\mathrm{YANG}^{3}$, Ying-hui $\mathrm{LI}^{3}$, Xin-min LIU ${ }^{\dagger 1,2}$ \\ $\left({ }^{1}\right.$ Research Center of Pharmacology and Toxicology, Institute of Medicinal Plant Development (IMPLAD), \\ Chinese Academy of Medical Sciences and Peking Union Medical College, Beijing 100193, China) \\ ( ${ }^{2}$ Division of Stem Cell Regulation and Application, Hunan University of Chinese Medicine, Changsha 410208, China) \\ $\left({ }^{3}\right.$ Science and Technology on Human Factors Engineering Laboratory, Astronaut Centre of China, Beijing 100193, China) \\ †E-mail: liuxinmin@hotmail.com \\ Received Dec. 18, 2015; Revision accepted Jan. 21, 2016; Crosschecked June 18, 2016
}

\begin{abstract}
Objectives: The aim of the study is to evaluate the cognitive-enhancing effects of hydrolysate of polygalasaponin (HPS) on senescence accelerate mouse P8 (SAMP8) mice, an effective Alzheimer's disease (AD) model, and to research the relevant mechanisms. Methods: The cognitive-enhancing effects of HPS on SAMP8 mice were assessed using Morris water maze (MWM) and step-through passive avoidance tests. Then $N$-methyl-D-aspartate (NMDA) receptor subunit expression for both the cortex and hippocampus of mice was observed using Western blotting. Results: HPS (25 and $50 \mathrm{mg} / \mathrm{kg}$ ) improved the escape rate and decreased the escape latency and time spent in the target quadrant for the SAMP8 mice in the MWM after oral administration of HPS for $10 \mathrm{~d}$. Moreover, it decreased error times in the passive avoidance tests. Western blotting showed that HPS was able to reverse the levels of NMDAR1 and NMDAR2B expression in the cortex or hippocampus of model mice. Conclusions: The present study suggested that HPS can improve cognitive deficits in SAMP8 mice, and this mechanism might be associated with NMDA receptor (NMDAR)-related pathways.
\end{abstract}

Key words: Cognitive improvement, Hydrolysate of polygalasaponin, SAMP8 mice http://dx.doi.org/10.1631/jzus.B1500321

CLC number: R964

\section{Introduction}

Alzheimer's disease (AD), a progressive neurodegenerative disorder, is one of the most common forms of dementia in the aged population (Blennow et al., 2006; Pike et al., 2006). The global prevalence of dementia is estimated to be more than 24 million,

\footnotetext{
${ }^{\ddagger}$ Corresponding author

" Project supported by the Medicinal Science and Technology Research Project (No. BWS11J052), the Ministry of Science and Technology of China (No. 2012ZX09J12201), and the Department of Science and Technology of Xinjiang Uygur Autonomous Region, China (No. 201491174)

(1) ORCID: Pan XU, http://orcid.org/0000-0001-9324-1513

(C) Zhejiang University and Springer-Verlag Berlin Heidelberg 2016
}

and is predicted to double every 20 years through to 2040 (Reitz et al., 2011). The main symptom of AD is cognitive impairment, which places a burden on patients and their families (Beal, 1995). Thus it is extremely important to search for treatments which could prevent or retard AD-related cognitive deficit. The amyloid cascade hypothesis is a genetic model which postulates that $\mathrm{AD}$ is due to an imbalance in the generation and clearance of amyloid- $\beta(\mathrm{A} \beta)$. This has been well accepted during the past few decades, but has led to only a few effective therapies, which provide symptomatic improvement alone and do less to prevent neurodegeneration (Misra and Medhi, 2013). In recent years, sporadic $\mathrm{AD}$ has been proposed to be a metabolic disease, as the neuroenergetic perspective 
posits that the primary cause of $\mathrm{AD}$ is an age-induced energy deficit in the mitochondrial activity of neurons, and that the up-regulation of oxidative phosphorylation is a compensatory mechanism (Demetrius and Driver, 2013; Anand et al., 2014). The Inverse Warburg hypothesis includes analytic integration of mitochondrial energetics in neurons with the cytosolic energetics in astrocytes, the concept of metabolic reprogramming, and the phenomenon of natural selection, which are more consistent with the hallmarks of sporadic AD (Demetrius et al., 2014; Grimm et al., 2016). Therefore, a model based on the neuroenergetic perspective could be potentially beneficial in drug and disease research.

The senescence accelerate mouse P8 (SAMP8) is one of the senescence-accelerated strains; these mice show a natural age-related overexpression of $\mathrm{A} \beta$ and an altered energy metabolism from a young age (5-6 months). SAMP8 mice are a metabolic model which not only exhibits the cognitive deficits that erode acquisition and memory retention, as shown in AD (Flood and Morley, 1998; Armbrecht et al., 2014) but also displays pathological changes such as $\mathrm{A} \beta$ peptide deposition (Takemura et al., 1993), cholinergic system dysfunction (Strong et al., 2003), disturbed synaptic plasticity (López-Ramos et al., 2012), and overexpression of amyloid precursor protein (APP) (Morley et al., 2012). Besides this, SAMP8 mice show neuroenergetic imbalances including a decrease in mitochondrial glutathione (GSH) content, Mn-superoxide dismutase (MnSOD), Cu/Zn-SOD, catalase activity, complex IV activity, and adenosine5'-triphosphate (ATP) levels (Xu et al., 2007; Shi et al., 2010). On the other hand, senescenceaccelerated resistant mouse 1 (SAMR1) of normal aging exhibits no senescence-related neuronal phenotypes and has a genetic background similar to that of SAMP8; it has been used extensively as a control (Takeda, 2009; Bayod et al., 2015).

Polygala tenuifolia Willd. ("Yuanzhi" in Chinese) is a well-known traditional Chinese medicine (TCM) herb, which was first documented in Shen Nong Ben Cao Jing, and its dried root has for a long time been traditionally used to treat memory loss in Asian countries (Howes and Houghton, 2003; Kwon et al., 2004; Adams et al., 2007). Recent pharmacological studies have shown that $P$. tenuifolia could improve memory impairment caused by scopolamine, stress, glutamate, and $\mathrm{A} \beta$, and promote neuronal proliferation in normal brains (Chung et al., 2002; Lin et al., 2012; Li et al., 2014). Polygalasaponins, such as polygalasaponin B, F, G, and XXXII, are the main components responsible for the action of $P$. tenuifolia and have been shown to improve cognitive impairment in AD effectively (Ikeya et al., 2004; Xu et al., 2009; Wu et al., 2014). However, reports have shown that polygalasaponins could be toxic to animals, leading to nose bleeding, gastrointestinal tract abnormality, and even death (Xue et al., 2009; Lin et al., 2012), which seriously limits their application and development. Recently, researchers have found that the hydrolysate of polygalasaponin (HPS) could attenuate or abrogate the toxicity (Lacaille-Dubois and Mitaine-Offer, 2005). This makes HPS a better choice in dementia treatment.

Although previous studies have shown the effects of polygalasaponins or HPS on learning and memory (Xu et al., 2011; Sun et al., 2012), pharmacological studies on SAMP8 mice, an excellent rodent metabolic AD model, have seldom been reported. In the present study, the improvement effect of HPS on cognitive deficits in SAMP8 mice was evaluated by carrying out behavioral tests. Further exploration indicated that the mechanism underlying cognitive improvement may be related to $N$-methyl-D-aspartate receptor (NMDAR) subtype expression in the hippocampus and cortex of mice.

\section{Materials and methods}

\subsection{HPS}

Dried root bark samples of $P$. tenuifolia Willd. were offered by the Company of Chinese Materia Medica in Beijing (China) and identified by Prof. Rui-le PAN of the Institute of Medicinal Plant Development, Chinese Academy of Medical Sciences and Peking Union Medical College (Beijing, China). The voucher specimen was deposited in the Herbarium of the Institute (No. 20090815). HPS was prepared according to our previous method (Xu et al., 2011). The chopped dry roots $(1 \mathrm{~kg})$ were exhaustively extracted using boiling water for $1 \mathrm{~h}$. After four rounds of extraction, the whole filtered liquid was passed through a D101 macroporous resin column and elution was carried out with water, $30 \%$ ethanol, and $95 \%$ ethanol 
in succession. The $95 \%$ eluent was concentrated and hydrolyzed for $4 \mathrm{~h}\left(\mathrm{pH} 14,100^{\circ} \mathrm{C}\right)$. Then hydrolysate was loaded into the D101 macroporous resin column. The $95 \%$ ethanol eluent was evaporated under vacuum to yield HPS ( $25 \mathrm{~g}$ ).

The HPS was in the form of a pale yellow powder. It was analyzed by high-performance liquid chromatography (HPLC; Waters, 600E pump, 2487 UV detectors and Empower software). A LiChroCART C18 column $(5 \mu \mathrm{m}, 250 \mathrm{~mm} \times 4.6 \mathrm{~mm}$; Merck, Darmstadt, Germany) and a 210-nm detection wavelength were used. Gradient elution of A (methanol $(\mathrm{MEOH}))$ and $\mathrm{B}\left(0.1 \%, \mathrm{H}_{3} \mathrm{PO}_{4} / \mathrm{H}_{2} \mathrm{O}\right)$ was carried out in the following combinations: $0 \mathrm{~min}, 30 \% \mathrm{~A} ; 60 \mathrm{~min}$, $90 \% \mathrm{~A}$. The flow rate was $1 \mathrm{ml} / \mathrm{min}$. For the reference compounds tenuifolin, 3,4,5-trimethoxy cinnamic acid, p-methoxy cinnamic acid, and fallax saponin A (95.6\%, 98.0\%, 98.3\%, and 96.4\%; National Institutes for Food and Drug Control), the contents of the corresponding chemicals in the HPS were 289.5, $247.1,770.0$, and $197.2 \mathrm{mg} / \mathrm{g}$, respectively.

\subsection{Animals}

Male SAMP8 and SAMR1 mice were purchased from the First Affiliated Hospital of Tianjin University of Traditional Chinese Medicine, China (8 months old, Certification No. 2006-006). Each mouse was individually housed in a constant temperature of $(25 \pm 2){ }^{\circ} \mathrm{C}$ and humidity of $(55 \pm 10) \%$ under a 12-h light-dark cycle (lights turned on at 7:00 a.m.). All mice received a standard rodent diet and tap water ad lib in the SPF animal house. All animal experiments were conducted in compliance with the Guide for the Care and Use of Laboratory Animals of the Institute of Medicinal Plant Development (Chinese Academy of Medical Sciences and Peking Union Medical College).

\subsection{Drug administration and experiment design}

Specific amounts of HPS and donepezil (DON) were weighed and dissolved in water to prepare the administration solutions. Mice were allowed 1 week to adapt to their environment before grouping. Fortyeight SAMP8 mice were equally divided into HPS groups (50 and $25 \mathrm{mg} /(\mathrm{kg} \cdot \mathrm{d})$ ), a donepezil group $(5 \mathrm{mg} /(\mathrm{kg} \cdot \mathrm{d})$ ), and a model group (given water) randomly; 12 SAMR1 mice were treated with water as a control group. Then the mice were orally administrated with the corresponding solutions in their own groups from the first day for $10 \mathrm{~d}$ before testing.

The oral administration was given without interruption during the behavioral test phase. As Fig. 1 shows, mice were sequentially tested by an open-field test (Day 11), a Morris water maze (MWM) (Days 12 to 21), and step-through passive avoidance (Days 22 to 23). Then, the mice were decapitated, and the cortex and hippocampus were dissected for measurement of NMDARs.

\subsection{Behavioral test}

\subsubsection{Open-field test}

The locomotor activity of the mice was assessed using an open-field computer-aided control system (Dang et al., 2009; Wang et al., 2010). The apparatus contained four metal tanks (diameter $30 \mathrm{~cm}$, height $40 \mathrm{~cm}$ ) with a 120 Lux light source on the ceiling, and a video camera fixed at the top to monitor the mouse activity. At $30 \mathrm{~min}$ after drug administration, each mouse was placed at the center of the tank and allowed to explore freely for $5 \mathrm{~min}$. The total distances travelled during the following $10 \mathrm{~min}$ were recorded automatically. Four mice were tested simultaneously.

\subsubsection{Morris water maze test}

The MWM test was used to evaluate spatial learning and memory following the procedures of Morris, with modifications (Morris, 1984; Hooge and de Deyn, 2001). The test included a visible platform trial, acquisition, probing, and a working memory trial. A black circular tank was filled with water (temperature $24-26{ }^{\circ} \mathrm{C}$ ), in which a hyaline platform

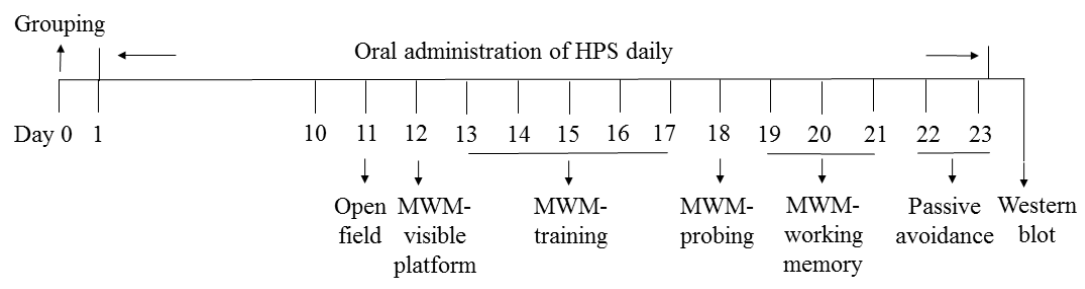

Fig. 1 Experimental procedure 
(diameter $6 \mathrm{~cm}$, height $15 \mathrm{~cm}$ ) was located. The water was made opaque by addition of ink, and its surface and the platform location could be adjusted in different test phases. Mouse swimming activity was monitored using a video camera overhead and recorded via a computerized tracking and image analyzer system.

In the visible platform trial, the water surface was adjusted to be $1.0 \mathrm{~cm}$ below the platform. Mice underwent 3 successive trials during $1 \mathrm{~d}$ : they were released at the opposite side of the platform, the location of which changed each trial, and were tested to see whether they could find the platform within $60 \mathrm{~s}$. Before and after swimming, the mice were left on the platform for $10 \mathrm{~s}$. In the acquisition phase, the fixed platform was submerged $1.0 \mathrm{~cm}$ beneath the surface. Each mouse underwent four successive trials a day for $5 \mathrm{~d}$. The mouse was placed on the platform for $10 \mathrm{~s}$, and then randomly released into one quadrant If the mouse failed to find the platform within $60 \mathrm{~s}$, it was guided to the platform and stayed there for $10 \mathrm{~s}$. In the probing phase, the platform was removed. Each mouse was released from the quadrant opposite from the previous platform location (the target quadrant) to swim freely for $60 \mathrm{~s}$. In the spatial working memory trial carried out for $3 \mathrm{~d}$, mice were placed on the opposite site of the platform, the location of which changed every day. Each mouse was tested 3 times per day. Finally, the recorded indicators including escape latency, escape rate, the average speed, total swimming distance, crossing number, and the time spent in the target quadrant were analyzed.

\subsubsection{Passive avoidance test}

The passive avoidance test was performed as for the previous method with modifications (Senechal et al., 2008; Xu et al., 2011). The trough-shaped apparatus consisted of a white illuminated chamber and a dark chamber separated by a guillotine door $(17.0 \mathrm{~cm} \times 13.5 \mathrm{~cm} \times 25.0 \mathrm{~cm})$. After $180 \mathrm{~s}$ of habitation 3 times, each mouse was placed in the light chamber and allowed to explore with the opened door for training. When it entered the dark chamber, the mouse got an electric shock to its foot $(50 \mathrm{~V})$ for $5 \mathrm{~s}$ with the door closed. Then the mouse was removed from the dark chamber and returned to its home cage. Twenty-four hours later, memory retention was tested in the same way as the acquisition trial, and the initial latency to enter the dark chamber and error times were recorded. The latency was recorded up to a maximum of $300 \mathrm{~s}$.

\subsection{Tissue preparation}

Immediately upon completion of the final behavior test, all mice were anesthetized and sacrificed. Their brains were rapidly removed, and the hippocampi and cortices were isolated and placed on ice. They were weighed and stored at $-80{ }^{\circ} \mathrm{C}$ before carrying out Western blotting.

\subsection{Measurements of NMDAR1 and NMDAR2B using Western blotting}

The hippocampi were sonicated in a cold lysis buffer with protease inhibitors (a buffer containing $1 \%$ phenylmethylsulfonyl fluoride (PMSF), $1 \%$ cocktail, and $1 \%$ protease inhibitor cocktail). After $30 \mathrm{~min}$ incubation on ice, the samples were centrifuged at $12000 \mathrm{r} / \mathrm{min}\left(10 \mathrm{~min}, 4^{\circ} \mathrm{C}\right)$. The supernatants were collected and removed for measurement of total protein concentration. A total of $50 \mu \mathrm{g}$ protein lysates were separated by sodium dodecyl sulfatepolyacrylamide gel electrophoresis (SDS-PAGE) and electro-transferred onto a polyvinylidene difluoride (PVDF) transfer membrane. Membranes were blocked in a 5\% non-fat dry milk solution, and then incubated overnight at $4{ }^{\circ} \mathrm{C}$ with the antibodies, namely NMDAR1 (D6587) and NMDAR2B, which were obtained from Cell Signaling Technology, Beverly, MA, USA. After three washes with Trisbuffered saline with Tween 20 (TBST), the membranes were incubated with horseradish peroxidaseconjugated secondary antibody for $120 \mathrm{~min}$ (1:5000; Applygen Technologies Inc., Beijing, China) at room temperature. Any excess of secondary antibodies was washed off, and the immunoreactive bands were visualized using a chemiluminescence kit (Pierce, Thermo Scientific, MA, USA). Mouse glyceraldehyde3-phosphate dehydrogenase (GAPDH, Zhongshan Jinqiao Biotechnology Company, Beijing, China) was used as an internal protein control. Quantification of the band density was performed by densitometric analysis using Image Lab Software.

\subsection{Statistical analysis}

Statistical analyses were performed using SPSS 19.0 and GraphPad Prism 5.0. Data from all procedures were expressed as mean \pm standard error of the mean (SEM). Indexes in acquisition trials, such as 
escape latency, distance, and speed in MWM test, were analyzed by repeated-measure two-way analysis of variance (ANOVA). The other behavior results, the biochemical concentration changes, and the expressions of proteins were analyzed by one-way ANOVA followed by Tukey's post hoc test. For all statistical tests, $P<0.05$ was considered to be significant.

\section{Results}

\subsection{Behavioral analysis}

\subsubsection{HPS does not affect locomotion in SAMP8 mice}

As shown in Fig. 2, HPS (25 and $50 \mathrm{mg} / \mathrm{kg}$ ) had no significant effect on locomotor activities, although the total distance was slightly reduced in the HPS $(50 \mathrm{mg} / \mathrm{kg})$ group compared with the SAMP8 group $(P=0.277)$. DON $(5 \mathrm{mg} / \mathrm{kg})$ also produced a shorter total distance than the model groups, without significance $(P=0.469)$.

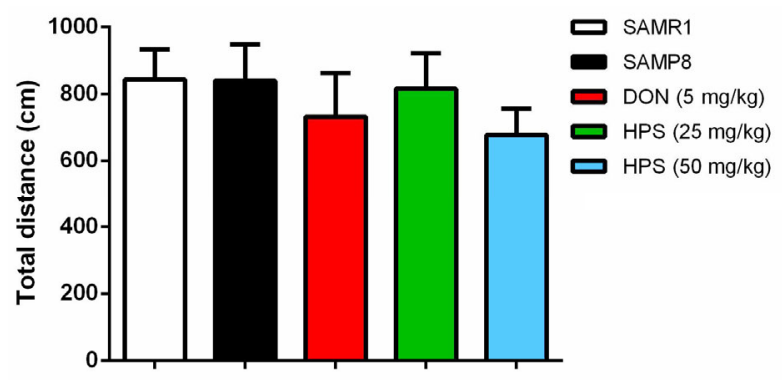

Fig. 2 Effect of HPS on locomotor activities of mice The total distance travelled by the mice was measured on Day 10 of the administration of HPS ( 25 and $50 \mathrm{mg} / \mathrm{kg}$ ). Data are expressed as mean \pm SEM; $n=10-12$ for each group

\subsubsection{HPS improves the spatial memory of SAMP8} mice in the MWM

In the visible platform trial (Fig. 3), there was no significant difference in total escape for all of the groups in any test, which means that all of the mice had no vision, sensation, or motor system function deficits, and could receive the following training.

For the memory acquisition trials (Fig. 4a), there was a significant difference in escape latencies between groups $\left(F_{(4,250)}=17.998, P<0.01\right)$, but not between training days $\left(F_{(4,250)}=1.644, P>0.05\right)$. The SAMP8 mice had a longer escape latency than the SAMR1 mice from the second day $(P<0.05)$, and HPS $(50 \mathrm{mg} / \mathrm{kg})$ administration was able to significantly

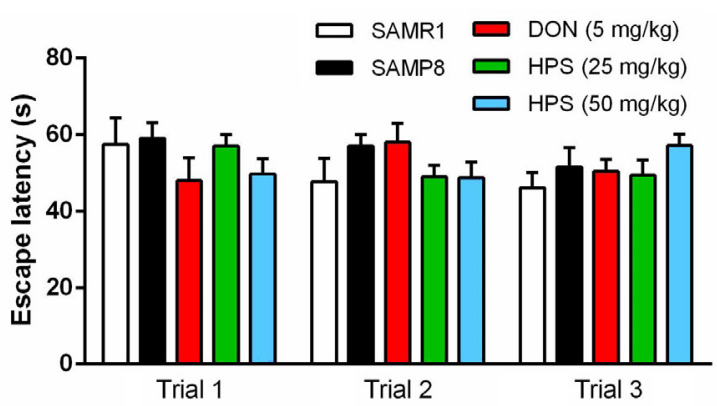

Fig. 3 Effect of HPS and model on visible platform test of MWM

The escape latencies of mice were tested 3 times on Day 11. Data were presented as mean \pm SEM; $n=10-12$ for each group

shorten this prolongation of latency on the second $(P<0.01)$, third $(P<0.01)$, and fourth $(P<0.05)$ days of the training trials; for low-dose HPS $(25 \mathrm{mg} / \mathrm{ml})$, there was an effect at the second and third days $(P<0.05)$. DON $(5 \mathrm{mg} / \mathrm{kg})$ did not have an effect until the fifth day $(P<0.05)$.

For the escape rate, the main effects for day and group were both statistically significant $\left(F_{(4,250)}=\right.$ 4.675, $\left.P<0.05 ; F_{(4,250)}=21.361, P<0.01\right)$. The SAMP8 mice maintained lower escape rates than the SAMR1 mice, with statistical significance, from the second day (Fig. $4 \mathrm{~b}, P<0.01)$. HPS $(50 \mathrm{mg} / \mathrm{kg})$ treatment significantly increased the escape rates of the SAMP8 mice between the second and fifth days $(P<0.01)$, and HPS $(25 \mathrm{mg} / \mathrm{kg})$ showed an effect on the second $(P<0.05)$, third $(P<0.01)$, and fifth $(P<0.05)$ days. However, HPS had no significant influence on the swimming speed of the SAMP8 mice (Fig. 4c).

In the probe trial (Figs. 5a and 5b), the SAMP8 mice had a significant decrease compared with the SAMR1 mice in crossing number $(P<0.05)$ and time spent in the target quadrant $(P<0.01)$. HPS treatment significantly increased the time spent in the target quadrant for the SAMP8 mice $(50 \mathrm{mg} / \mathrm{kg}, P<0.05)$. Besides this, the HPS-treated mice were more likely to cross the platform point.

The working memory trial assessed the ability of the mice to learn new messages. In the escape latency test (Fig. 5c), the main effect for the group was statistically significant $\left(F_{(4,250)}=6.412, P<0.01\right)$. The SAMP8 mice showed a significant increase in escape latency compared with the SAMR1 mice (Days 1 and 2, $P<0.01$; Day $3, P<0.05$ ); HPS administration decreased latency prolonging during the first day 

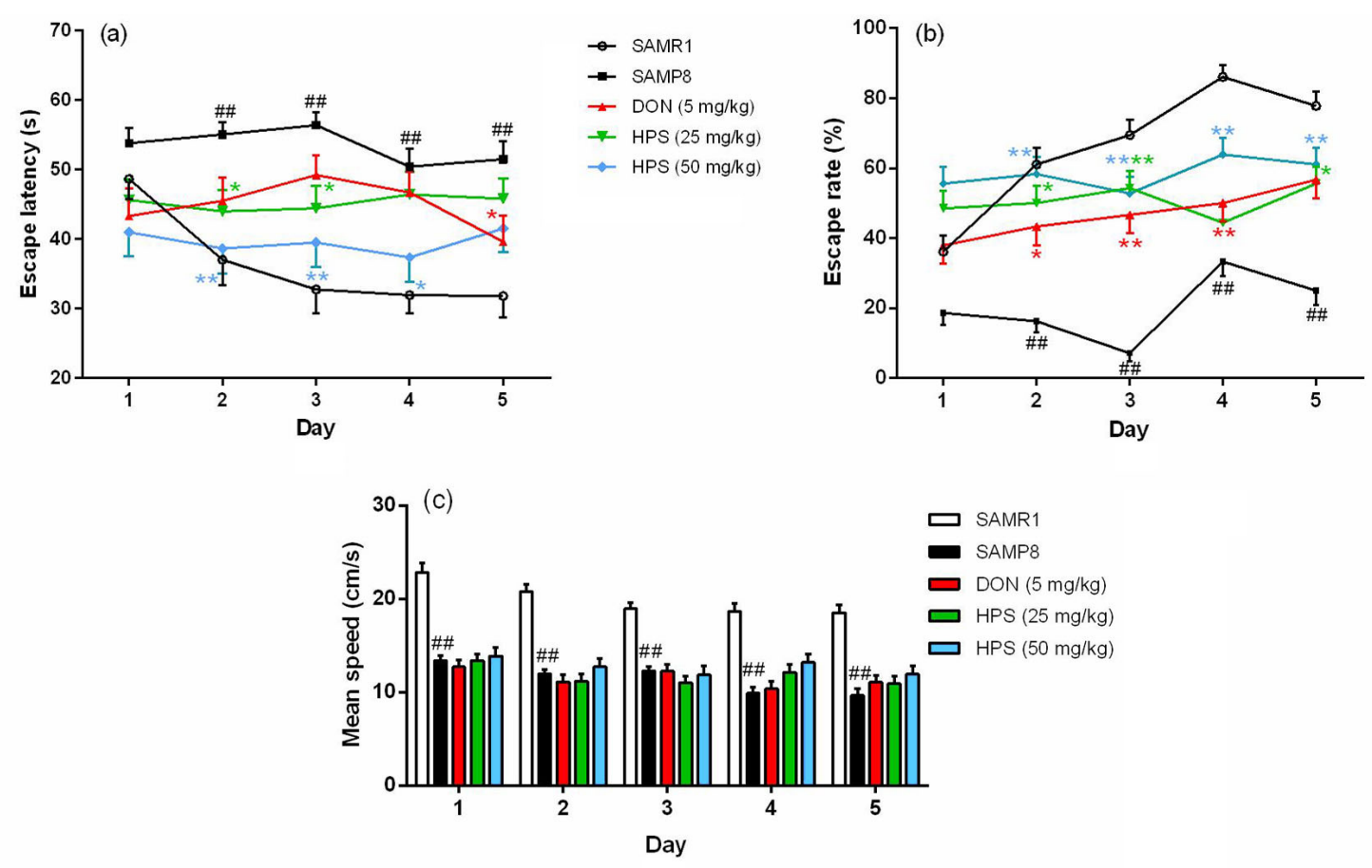

Fig. 4 Effect of HPS on the acquisition of spatial memory of aged SAMP8 mice in the MWM

Training trials were performed on Day 9 after HPS administration. Escape latency (a), escape rate (b), and mean speed of mice (c) to find the fixed hidden platform across the 5 training days ( 3 trials per day). Data are expressed as mean \pm SEM; $n=10-12$ for each group. ${ }^{\#} P<0.05,{ }^{\#} P<0.01$, compared with the SAMR1 group, ${ }^{*} P<0.05,{ }^{* *} P<0.01$, compared with the aged SAMP8 group
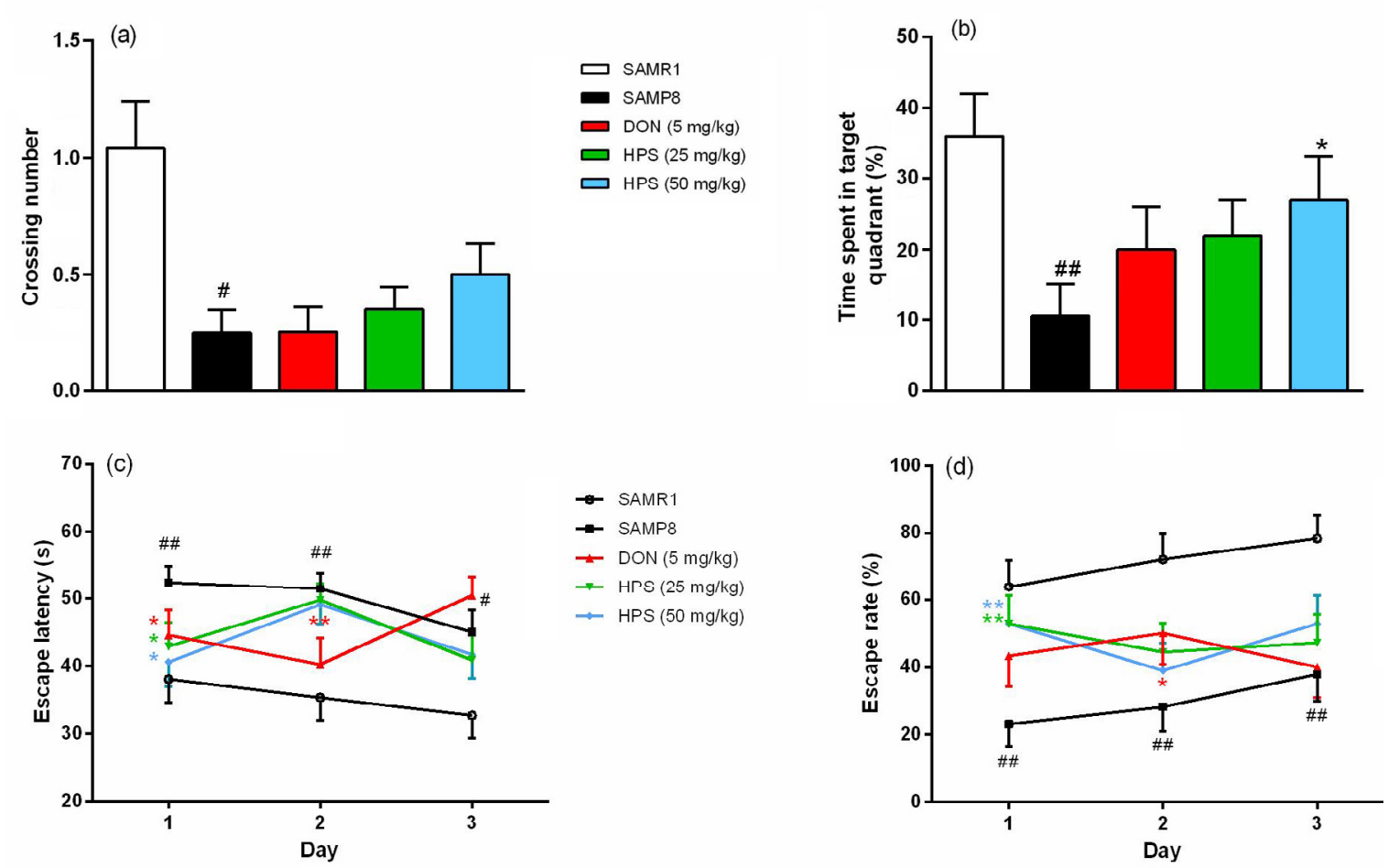

Fig. 5 Effect of HPS on probing and working memory of aged SAMP8 mice in the MWM

The probe trial was performed $24 \mathrm{~h}$ after the last training. Crossing numbers (a) and swimming time (b) spent in the target quadrant during which the mice attempted to probe the previous platform. Escape latency (c) and escape rate (d) of mice to find the hidden platform during the working memory test. Values are presented as mean \pm SEM; $n=10-12$ for each group. ${ }^{\#} P<0.05$, ${ }^{\#} P<0.01$, compared with the SAMR1 group, ${ }^{*} P<0.05,{ }^{* *} P<0.01$, compared with the aged SAMP8 group 
$(P<0.05)$. DON showed an effect on Days 1 and 2 . For the escape rate test (Fig. 5d), the influence of the group was also significant $\left(F_{(4,250)}=9.142, P<0.01\right)$. The SAMP8 mice had lower escape rates than the SAMR1 mice $(P<0.01)$; HPS significantly increased this rate on the first day $(P<0.01)$, while DON produced an effect on Day 2. It is interesting to discover that HPS and DON took effect on different time courses. HPS was able to improve the working memory of the model on the first day, while DON had good performance during the first two days. This may due to the different brain areas they influence, which needs further research.

3.1.3 HPS improves cognitive deficits, assessed by a step-through passive avoidance task

Improved cognitive ability for the SAMP8 mice was indicated by the significantly lower first escape latency and greater number of errors than those of the SAMR1 mice. HPS $(50 \mathrm{mg} / \mathrm{kg})$ treatment prolonged the first escape latency and reduced the number of errors for the SAMP8 mice significantly. DON also improved cognitive ability, but this was not significant. This may be because of the large inter-mouse variability and the limitation of a small sample number (Fig. 6).

\subsection{Effect of HPS on the expressions of NMDAR1 and NMDAR2B in the hippocampus and cortex of SAMP8 mice}

Statistical analysis revealed a significant effect of group on NMDAR1 expression in the hippocampus $(F=6.618, P<0.01)$, but not in the cortex $(F=0.626, P>0.05)$ (Fig. 7a). Compared with the SAMR1 mice, the NMDAR1 expression in the hippocampus of the SAMP8 mice decreased by $56 \%$
$(P<0.01$; Fig. $7 \mathrm{~b})$. HPS ( 25 and $50 \mathrm{mg} / \mathrm{kg})$ treatment significantly increased the NMDAR1 level of the SAMP8 mice $(P<0.05)$. In contrast, the difference of NMDAR2B expression among the groups was significant in the cortex $(F=210.9, P<0.01)$, but not in the hippocampus $(F=0.668, P>0.05)$. The NMDAR2B expression in the cortex of the SAMP8 mice decreased by $58 \%$ compared with the SAMR 1 mice $(P<0.01$, Fig. $7 \mathrm{c})$, but this level for the SAMP8 mice was up-regulated for the HPS group ( 25 and $50 \mathrm{mg} / \mathrm{kg}$, $P<0.05)$.

\section{Discussion}

The current study appears for the first time to demonstrate that in the SAMP8 model, HPS can effectively improve learning and memory capacities and the anti-amnesia effect may be related to the NMDAR expression level.

\subsection{SAMP8 is a good model for AD}

The sporadic AD model used in drug research should not only show the cognitive deficits over specific time courses, but also imitate the pathological mechanisms underlying neuronal function (Webster et al., 2014). SAM was developed from the AKR/J strain mice originally based on the data of the grading score for life span, senescence, and pathologic phenotypes. SAMP8 mice have been used as a senescenceaccelerated model in neuroscience research, as they could show early onset of deficits in learning and memory and provide valuable insights into physiological and pathological changes of $\mathrm{AD}$ (Butterfield and Poon, 2005). In this study, we found that, compared with age-matched SAMR1 mice, aged
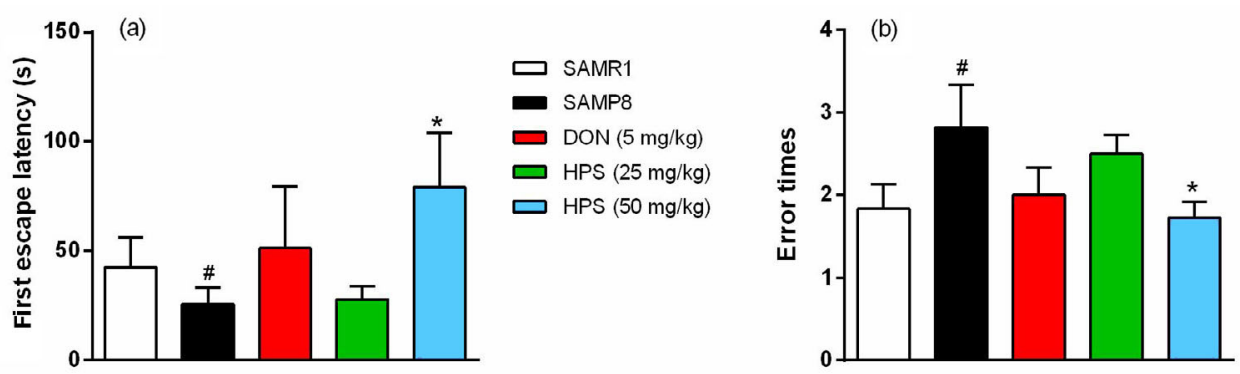

Fig. 6 Effect of HPS on memory of the aged SAMP8 mice in the step-through passive avoidance tests The first latency (a) and the number of errors (b) the mice made in escaping into the dark chamber during the memory consolidation tests. Data are shown as mean \pm SEM; $n=10-12$ in each group. ${ }^{\sharp} P<0.05$, compared with the SAMR 1 group; ${ }^{*} P<0.05$, compared with the SAMP8 group 
(a)
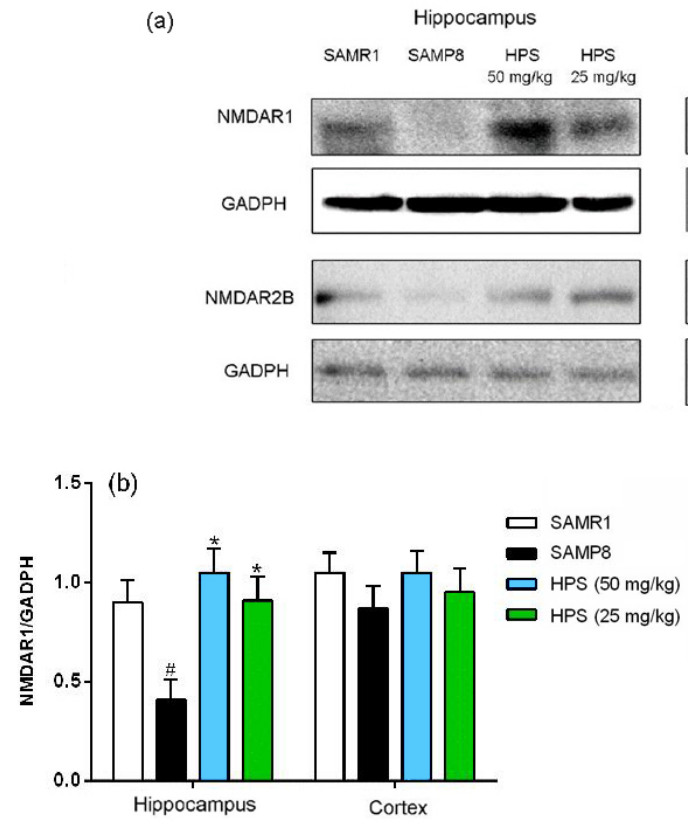
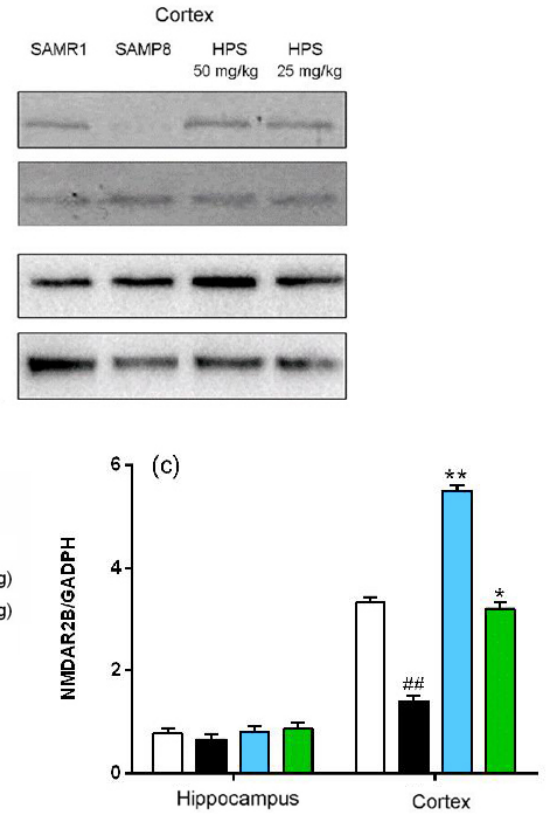

Fig. 7 Effect of HPS on NMDAR1 and NMDAR2B in the hippocampus and cortex of SAMP8 mice

(a) Representative Western blotting of NMDAR1 and NMDAR2B. GADPH was used as a control for protein loading. Densitometric analysis of NMDAR1 (b) and NMDAR2B (c) test bands were normalized to GADPH and expressed as relative fold compared with control. The values are expressed as mean \pm SEM of at least three independent experiments. ${ }^{\#} P<0.05,{ }^{\#} P<0.01$, compared with the SAMR1 group; ${ }^{*} P<0.05,{ }^{* *} P<0.01$, compared with the SAMP8 group

SAMP8 mice showed a deficient performance in the MWM test and declined passive avoidance in the step-through test, which are controlled by the hippocampus and cortex. The remarkable decline in cognitive ability in the SAMP8 mice is consistent with previous reports (Flood and Morley, 1998; Armbrecht et al., 2014). Besides this, our results indicated the decrease of NMDAR subunit expression in the hippocampus or cortex of SAMP8 mice, which is similar to the other reports that also found deficits in the glutamatergic system of SAMP8 mice (Yang et al., 2005; Huang et al., 2012). These changes indicated that SAMP8 mice could be considered to be a good model for AD.

\subsection{HPS ameliorates the cognitive impairment of SAMP8}

Though polygalasaponins were widely reported to be effective in improving learning and memory, the toxicity, which produced nose bleeding, gastrointestinal tract abnormality and even death, limited their development and use. HPS, including tenuifolin, 3,4,5-trimethoxy cinnamic acid, $p$-methoxycinnamic, and fallax saponin $\mathrm{A}$, was obtained by carrying out
$4 \mathrm{~h}$ of alkaline hydrolysis of polygalgasaponins. Reports suggested that the hydrolysis process could remove the oligosaccharidic ester chain at C-28, which might be responsible for the toxicity of the saponins (Lacaille-Dubois and Mitaine-Offer, 2005). Our previous report also showed that HPS could markedly decrease toxicity (Xu et al., 2011). Besides this, the pharmacokinetic studies found that 3,4,5-trimethoxy cinnamic acid, $p$-methoxycinnamic acid, and tenuifolin could be absorbed rapidly into the circulation and reached their peak concentrations (Wang et al., 2015). Tenuifolin can cross the blood brain barrier quickly and remain in the body longer, although it has lower oral bioavailability (Ma et al., 2014). These material bases make it rational and meaningful for researching the effect of HPS on memory loss.

Functional evaluation is one of the most reliable indicators reflecting levels of animal intelligence. The MWM is used to evaluate spatial memory through different trial designs, among which training and probing tests reflect long-time memory and the working memory test indicates short-term memory (Hooge and de Deyn, 2001). Passive avoidance ability was assessed by the step-through test, which depends 
on the ability to retain and recall information (Sun et al., 2012). Those test results demonstrated that HPS consumption effectively improves impaired learning and memory in aged SAMP8 mice. The efficacy of HPS was dose-dependent, and for the different indicators the HPS of high concentration $(50 \mathrm{mg} / \mathrm{kg})$ always showed statistical significance when compared with the control group. Low-dose HPS administration also showed a clear effect, except in the probing and step-though tests. However, HPS did not influence locomotor activity, visible platform performance, or the swim speed of SAMP8 mice, which suggests that the amelioration effect of HPS is to be mnemonic in origin, rather than provoked by sensorimotor effects.

It was interesting to find that HPS and DON had different effect times and potencies. For instance, in the working memory trial, HPS significantly decreased latency prolonging and increased escape rate on the first day, while DON showed an effect during the first two days. This may be due to the different brain areas they influence or the way in which they take effect, which needs to be studied further. In our research, DON also showed a cognitive enhancement effect during MWM training: it significantly decreased the escape latency on the fifth day and increased the escape rate between the second and fourth days. This was different from reports which have found that DON had an effect between the third and fifth days (Cachard-Chastel et al., 2008; Goverdhan et al., 2012). We speculated that a difference in effect time or potency may be due to differences in model, animal, or route drug received.

\subsection{HPS treatment reverses the changes in level of NMDA subunits}

NMDARs are cationic channels gated by the neurotransmitter glutamate, containing the obligatory subunit GluN1 plus either GluN2B or GluN2A or both. Functional NMDARs have a crucial role in the induction of long-term potentiation (LTP), namely synaptic plasticity, which underlie memory and learning (Rebola et al., 2010). On the other hand, overactivation of NMDARs leads to cytosolic free intracellular calcium overload, causing excitotoxicity in the central nervous system (Parameshwaran et al., 2008). The different effects mediated by NMDARs are dependent on the levels or activation of NMDARs.
Although the exact molecular basis of $\mathrm{AD}$ remains uncertain, it is widely accepted that the cognitive deficits of AD have close relevance to the glutamatergic system (Zadori et al., 2014). Reports have indicated that the function of NMDARs decreases in $\mathrm{AD}$, including gene expression (Yashiro and Philpot, 2008), levels of mRNA and protein (Hynd et al., 2001), or neurotransmitters (Rupsingh et al., 2011). A decline in levels of NMDAR subunits has been observed in many AD models and clinical research (Hynd et al., 2004; Mishizen-Eberz et al., 2004; Kravitz et al., 2013), which is consistent with our result that NMDAR1 and NMDAR2B expression decreased in SAMP8 as compared with SAMR1 mice. The decreased level of NMDAR limited its normal functional role, leading to a deficit in learning and memory. It is a limitation of our work that we did not carry out further studies to verify that NMDAR at the normal level does not lead to neurotoxicity. According to our results, the HPS ( 25 and $50 \mathrm{mg} / \mathrm{kg}$ ) treatment reversed the decline in NMDA subunits in the hippocampus or cortex of the SAMP8 mice. This effect of HPS is consistent with the cognitive improvement. We presume that an increase in NMDA subunits makes certain the normal induction of LTP in SAMP8 mice, and the exact underlying mechanisms need to be explored further.

\section{Conclusions}

In summary, the results clearly demonstrated the improvement effect of HPS on cognitive deficit in the SAMP8 model, and the mechanisms underlying this might be related to changes in NMDAR expression after HPS administration. HPS may be a potential drug for treatment of cognitive deficit in AD with further experimentation needed to support this.

\section{Compliance with ethics guidelines}

Pan XU, Shu-ping XU, Ke-zhu WANG, Cong LU, Hong-xia ZHANG, Rui-le PAN, Chang QI, Yan-yan YANG, Ying-hui LI, and Xin-min LIU declare that they have no conflict of interest.

All institutional and national guidelines for the care and use of laboratory animals were followed.

\section{References}

Adams, M., Gmunder, F., Hamburger, M., 2007. Plants traditionally used in age related brain disorders-A 
survey of ethnobotanical literature. J. Ethnopharmacol., 113(3):363-381.

http://dx.doi.org/10.1016/j.jep.2007.07.016

Anand, R., Gill, K.D., Mahdi, A.A., 2014. Therapeutics of Alzheimer's disease: past, present and future. Neuropsychopharmacology, 76:27-50.

http://dx.doi.org/10.1016/j.neuropharm.2013.07.004

Armbrecht, H.J., Siddiqui, A.M., Green, M., et al., 2014. SAMP8 mice have altered hippocampal gene expression in LTP, phosphatidylinositol signaling, and endocytosis pathways. Neurobiol. Aging, 35(1):159-168. http://dx.doi.org/10.1016/j.neurobiolaging.2013.07.018

Bayod, S., Felice, P., Andrés, P., et al., 2015. Downregulation of canonical Wnt signaling in hippocampus of SAMP8 mice. Neurobiol. Aging, 36(2):720-729.

http://dx.doi.org/10.1016/j.neurobiolaging.2014.09.017

Beal, M.F., 1995. Aging, energy, and oxidative stress in neurodegenerative diseases. Ann. Neurol., 38(3):357-366. http://dx.doi.org/10.1002/ana.410380304

Blennow, K., Leon, M., Zetterberg, H., 2006. Alzheimer's disease. Lancet, 368(9533):387-403. http://dx.doi.org/10.1016/S0140-6736(06)69113-7

Butterfield, D.A., Poon, H.F., 2005. The senescenceaccelerated prone mouse (SAMP8): a model of agerelated cognitive decline with relevance to alterations of the gene expression and protein abnormalities in Alzheimer's disease. Exp. Geront., 40(10):774-783. http://dx.doi.org/10.1016/j.exger.2005.05.007

Cachard-Chastel, M., Devers, S., Sicsic, S., et al., 2008. Prucalopride and donepezil act synergistically to reverse scopolamine-induced memory deficit in $\mathrm{C} 57 \mathrm{Bl} / 6 \mathrm{j}$ mice. Behav. Brain Res., 187(2):455-461. http://dx.doi.org/10.1016/j.bbr.2007.10.008

Chung, I., Moore, N., Oh, W., et al., 2002. Behavioural pharmacology of polygalasaponins indicates potential antipsychotic efficacy. Pharmacol. Biochem. Behav., 71(1):191-195. http://dx.doi.org/10.1016/S0091-3057(01)00648-7

Dang, H.X., Chen, Y., Liu, X.M., et al., 2009. Antidepressant effects of ginseng total saponins in the forced swimming test and chronic mild stress models of depression. Prog. Neuro-Psychoph., 33(8):1417-1424. http://dx.doi.org/10.1016/j.pnpbp.2009.07.020

Demetrius, L.A., Driver, J., 2013. Alzheimer's as a metabolic disease. Biogerontology, 14(6):641-649. http://dx.doi.org/10.1007/s10522-013-9479-7

Demetrius, L.A., Magistretti, P.J., Pellerin, L., 2014. Alzheimer's disease: the amyloid hypothesis and the Inverse Warburg effect. Front. Physiol., 5:522. http://dx.doi.org/10.3389/fphys.2014.00522

Flood, J.F., Morley, J.E., 1998. Learning and memory in the SAMP8 mouse. Neurosci. Biobehav. Rev., 22(1):1-20. http://dx.doi.org/10.1016/S0149-7634(96)00063-2

Goverdhan, P., Sravanthi, A., Mamatha, T., 2012. Neuroprotective effects of meloxicam and selegiline in scopolamine-induced cognitive impairment and oxidative stress. Int. J. Alzheimers Dis., 2012:974013.

http://dx.doi.org/10.1155/2012/974013

Grimm, A., Friedland, K., Eckert, A., 2016. Mitochondrial dysfunction: the missing link between aging and sporadic Alzheimer's disease. Biogerontology, 17(2):281-296. http://dx.doi.org/10.1007/s10522-015-9618-4

Hooge, R.D., de Deyn, P.P., 2001. Applications of the Morris water maze in the study of learning and memory. Brain Res. Rev., 36(1):60-90. http://dx.doi.org/10.1016/S0165-0173(01)00067-4

Howes, M.J., Houghton, P.J., 2003. Plants used in Chinese and Indian traditional medicine for improvement of memory and cognitive function. Pharmacol. Biochem. Behav., 75(3):513-527.

http://dx.doi.org/10.1016/S0091-3057(03)00128-X

Huang, Y., Zhang, H., Yang, S., et al., 2012. Liuwei Dihuang decoction facilitates the induction of long-term potentiation (LTP) in senescence accelerated mouse/prone 8 (SAMP8) hippocampal slices by inhibiting voltage-dependent calcium channels (VDCCs) and promoting $N$-methyl-Daspartate receptor (NMDA) receptors. J. Ethnopharmacol., 140(2):384-390.

http://dx.doi.org/10.1016/j.jep.2012.01.030

Hynd, M.R., Scott, H.L., Dodd, P.R., 2001. Glutamate (NMDA) receptor NR1 subunit mRNA expression in Alzheimer's disease. J. Neurochem., 78(1):175-182. http://dx.doi.org/10.1046/j.1471-4159.2001.00409.x

Hynd, M.R., Scott, H.L., Dodd, P.R., 2004. Differential expression of $N$-methyl-D-aspartate receptor NR2 isoforms in Alzheimer's disease. J. Neurochem., 90(4):913-919. http://dx.doi.org/10.1111/j.1471-4159.2004.02548.x

Ikeya, Y., Takeda, S., Tunakawa, M., et al., 2004. Cognitive improving and cerebral protective effects of acylated oligosaccharides in Polygala tenuifolia. Biol. Pharm. Bull., 27(7):1081-1085. http://dx.doi.org/10.1248/bpb.27.1081

Kravitz, E., Gaisler-Salomon, I., Biegon, A., 2013. Hippocampal glutamate NMDA receptor loss tracks progression in Alzheimer's disease: quantitative autoradiography in postmortem human brain. PLOS ONE, 8(11):e81244. http://dx.doi.org/10.1371/journal.pone.0081244

Kwon, Y.S., Nabeshima, T., Shin, E.J., 2004. PAP 9704, a Korean herbal medicine attenuates methamphetamineinduced hyperlocomotion via adenosine $\mathrm{A}_{2 \mathrm{~A}}$ receptor stimulation in mice. Biol. Pharm. Bull., 27(6):906-909. http://dx.doi.org/10.1248/bpb.27.906

Lacaille-Dubois, M.A., Mitaine-Offer, A.C., 2005. Triterpene saponins from Polygalaceae. Phytochem. Rev., 4(2-3): 139-149. http://dx.doi.org/10.1007/s11101-005-2606-6

Li, Z.Y., Liu, Y.M., Wang, L.W., et al., 2014. Memoryenhancing effects of the crude extract of Polygala tenuifolia on aged mice. eCAM, 2014:392324. http://dx.doi.org/10.1155/2014/392324 
Lin, Z.H., Gu, J., Xiu, J., et al., 2012. Traditional Chinese medicine for senile dementia. eCAM, 2012:692621. http://dx.doi.org/10.1155/2012/692621

López-Ramos, J.C., Jurado-Parras, M.T., Sanfeliu, C., et al., 2012. Learning capabilities and CA1-prefrontal synaptic plasticity in a mice model of accelerated senescence. Neurobiol. Aging, 33(3):613-626. http://dx.doi.org/10.1016/j.neurobiolaging.2011.04.005

Ma, B., Li, X., Li, J., et al., 2014. Quantitative analysis of tenuifolin concentrations in rat plasma and tissue using LCMS/MS: application to pharmacokinetic and tissue distribution study. J. Pharm. Biomed. Anal., 88(25): 191-200. http://dx.doi.org/10.1016/j.jpba.2013.07.012

Mishizen-Eberz, A.J., Rissman, R.A., Carter, T.L., et al., 2004. Biochemical and molecular studies of NMDA receptor subunits NR1/2A/2B in hippocampal subregions throughout progression of Alzheimer's disease pathology. Neurobiol. Dis., 15(1):80-92. http://dx.doi.org/10.1016/j.nbd.2003.09.016

Misra, S., Medhi, B., 2013. Drug development status for Alzheimer's disease: present scenario. Neurol. Sci., 34(6) 831-839. http://dx.doi.org/10.1007/s10072-013-1316-x

Morley, J.E., Farr, S.A., Kumar, V.B., et al., 2012. The SAMP8 mouse: a model to develop therapeutic interventions for Alzheimer's disease. Curr. Pharm. Des., 18(8):1123-1130. http://dx.doi.org/10.2174/138161212799315795

Morris, R., 1984. Developments of a water-maze procedure for studying spatial learning in the rat. J. Neurosci. Method., 11(1):47-60. http://dx.doi.org/10.1016/0165-0270(84)90007-4

Parameshwaran, K., Dhanasekaran, M., Suppiramaniam, V., 2008. Amyloid beta peptides and glutamatergic synaptic dysregulation. Exp. Neurol., 210(1):7-13. http://dx.doi.org/10.1016/j.expneurol.2007.10.008

Pike, C.J., Rosario, E.R., Nguyen, T.V., 2006. Androgens, aging, and Alzheimer's disease. Endocrine, 29(2): 233-241. http://dx.doi.org/10.1385/ENDO:29:2:233

Rebola, N., Srikumar, B.N., Mulle, C., 2010. Activitydependent synaptic plasticity of NMDA receptors. $J$. Physiol., 588(1):93-99. http://dx.doi.org/10.1113/jphysiol.2009.179382

Reitz, C., Brayne, C., Mayeux, R., 2011. Epidemiology of Alzheimer disease. Nat. Rev. Neurol., 7(3):137-152. http://dx.doi.org/10.1038/nrneurol.2011.2

Rupsingh, R., Borrie, M., Smith, M., et al., 2011. Reduced hippocampal glutamate in Alzheimer disease. Neurobiol. Aging, 32(5):802-810. http://dx.doi.org/10.1016/j.neurobiolaging.2009.05.002

Senechal, Y., Kelly, P.H., Dev, K.K., 2008. Amyloid precursor protein knockout mice show age-dependent deficits in passive avoidance learning. Behav. Brain Res., 186(1):
126-132.

http://dx.doi.org/10.1016/j.bbr.2007.08.003

Shi, C., Xiao, S., Liu, J., et al., 2010. Ginkgo biloba extract EGb761 protects against aging-associated mitochondrial dysfunction in platelets and hippocampi of SAMP8 mice. Platelets, 21(5):373-379. http://dx.doi.org/10.3109/09537100903511448

Strong, R., Reddy, V., Morley, J.E., 2003. Cholinergic deficits in the septal-hippocampal pathway of the SAM-P/8 senescence accelerated mouse. Brain Res., 966(1): $150-156$ http://dx.doi.org/10.1016/S0006-8993(02)04192-6

Sun, F., Sun, J.D., Han, N., et al., 2012. Polygalasaponin F induces long-term potentiation in adult rat hippocampus via NMDA receptor activation. Acta Pharmacol. Sin., 33(4):431-437. http://dx.doi.org/10.1038/aps.2011.199

Takeda, T., 2009. Senescence-accelerated mouse (SAM) with special references to neurodegeneration models, SAMP8 and SAMP10 mice. Neurochem. Res., 34(4):639-659. http://dx.doi.org/10.1007/s11064-009-9922-y

Takemura, M., Nakamura, S., Akiguchi, I., et al., 1993. $\beta /$ A4 proteinlike immunoreactive granular structures in the brain of senescenceaccelerated mouse. Am. J. Surg. Pathol., 142(6):1887-1897.

Wang, Q., Sun, L.H., Jia, W., et al., 2010. Comparison of ginsenosides $\mathrm{Rg} 1$ and $\mathrm{Rb} 1$ for their effects on improving scopolamineinduced learning and memory impairment in mice. Phytoth. Res., 24(12):1748-1754.

http://dx.doi.org/10.1002/ptr.3130

Wang, Q., Xiao, B.X., Pan, R.L., et al., 2015. An LC-MS/MS method for simultaneous determination of three Polygala saponin hydrolysates in rat plasma and its application to a pharmacokinetic study. J. Ethnopharmacol., 169(1): 401-406. http://dx.doi.org/10.1016/j.jep.2015.04.033

Webster, S.J., Bachstetter, A.D., Nelson, P.T., et al., 2014. Using mice to model Alzheimer's dementia: an overview of the clinical disease and the preclinical behavioral changes in 10 mouse models. Front. Genet., 5(88):1-23. http://dx.doi.org/10.3389/fgene.2014.00088

Wu, M.M., Yuan, Y.H., Chen, J., et al., 2014. Polygalasaponin $\mathrm{F}$ against rotenone-induced apoptosis in PC12 cells via mitochondria protection pathway. J. Asian Nat. Prod. Res., 16(1):59-69. http://dx.doi.org/10.1080/10286020.2013.864283

Xu, J., Shi, C., Li, Q., et al., 2007. Mitochondrial dysfunction in platelets and hippocampi of senescence-accelerated mice. J. Bioenerg. Biomembr., 39(2):195-202. http://dx.doi.org/10.1007/s10863-007-9077-y

Xu, S.P., Yang, Y.Y., Xue, D., et al., 2011. Cognitiveenhancing effects of polygalasaponin hydrolysate in $\mathrm{A} \beta_{25-35}$-induced amnesic mice. eCAM, 2011:839720. http://dx.doi.org/10.1155/2011/839720

Xu, X.H., Zhou, J.F., Li, T.Z., et al., 2009. Polygalasaponin G 
promotes neurite outgrowth of cultured neuron on myelin. Neurosci. Lett., 460(1):41-46.

Xue, W., Hu, J.F., Yuan, Y.H., et al., 2009. Polygalasaponin XXXII from Polygala tenuifolia root improves hippocampal-dependent learning and memory. Acta Pharmacol. Sin., 30(9):1211-1219. http://dx.doi.org/10.1038/aps.2009.112

Yang, S., Qiao, H., Wen, L., et al., 2005. D-Serine enhances impaired long-term potentiation in CA1 subfield of hippocampal slices from aged senescence-accelerated mouse prone/8. Neurosci. Lett., 379(1):7-12. http://dx.doi.org/10.1016/j.neulet.2004.12.033

Yashiro, K., Philpot, B.D., 2008. Regulation of NMDA receptor subunit expression and its implications for LTD, LTP, and metaplasticity. Neuropharmacology, 55(7): 1081-1094. http://dx.doi.org/10.1016/j.neuropharm.2008.07.046

Zadori, D., Veres, G., Szalardy, L., et al., 2014. Glutamatergic dysfunctioning in Alzheimer's disease and related therapeutic targets. J. Alzheimers Dis., 42(3):177-187. http://dx.doi.org/10.3233/jad-132621

\section{中文概要}

题 目: 远志皇苷水解产物对 SAMP8 小鼠的益智作用 研究

目 的: 本文主要评价远志㿝苷水解产物 (HPS) 对 SAMP8 小鼠的益智作用, 并对相关机制进行探索。

创新点: HPS 相较于远志㿝苷有更高的安全性, 毒性显著 降低或消除; 本研究所用的 SAMP8 模型是一个 能较好地同时模拟阿尔兹海默病智力衰退及病 理变化的代谢性模型, 用于药效评价和机制研究 更加可靠。

方 法: 采用水迷宫 (图 4 和 5) 及避暗（图 6) 两种经 典的检测方法来评价药物的益智药效, 并进一步 用免疫印迹实验分析 $N$-甲基-D-天冬氨酸 (NMDA) 受体水平来对机制进行探索 (图 7)。

结 论: 本研究表明, HPS 能明显改善 SAMP8 小鼠的认 知损伤, 其作用机制与调控 NMDA 受体相关通 路有关。

关键词: 认知改善; 远志㿝苷水解产物; SAMP8 小鼠 